\title{
REPERTÓRIO, SEGUNDO CHARLES TILLY: HISTÓRIA DE UM CONCEITO ${ }^{1}$
}

Charles Tilly é um dos grandes nomes da sociologia do século XX, em particular da sociologia política. Seus trabalhos sobre movimentos sociais, publicados a partir dos anos 1970, são um divisor de águas no estudo do assunto, por combaterem explicações economicistas e psicologizantes, oferecendo, em contraponto, teoria que focaliza fatores eminentemente políticos na compreensão do processo de mobilização coletiva. Ao edificar tal teoria, Tilly se deu conta da necessidade - e da dificuldade - de incorporar dimensões culturais à explicação dos processos políticos. Amante da música, abordou a imbricação entre cultura e ação política valendo-se da noção de "repertório".

\section{PASSOS}

Charles Tilly (1929-2008) escreveu muito sobre muitas coisas: de desigualdade à urbanização, de metodologia à formação dos Estados nacionais, sobre guerra, violência coletiva e conflitos políticos, e se estabeleceu como um dos grandes nomes da sociologia da segunda metade do século XX. Aluno de Barrington Moore, Tilly se engajou desde os anos 1970 na pesquisa de mobilizações sociais, num antifuncionalismo feroz - registrado no nome de capítulo de seu As sociology meets history (1981): "Useless Durkheim".

Tilly se amparou nos outros dois clássicos para afirmar a prevalência do conflito como fenômeno estruturador da vida social. Pendeu, sobretudo, para o lado de Weber, ao enfatizar a lógica intrínseca dos conflitos políticos. Em vários escritos ao longo de três décadas, Tilly formulou sua Teoria do Processo Político (depois renomeada Teoria do Confronto Político), que explica o surgimento e o desenrolar de mobilizações coletivas mediante a reconstrução do contexto político, ou da estrutura de oportunidades e ameaças políticas, principalmente as relações de força entre as autoridades - grupos ocupando cargos no Estado -, e os desafiantes - que se encontram do lado de fora. Decisiva nesta relação seria a capacidade (ou perda dela) repressiva das primeiras e a disponibilida- 
de, para os segundos, de aliados potenciais dentre setores dissidentes da elite no poder. Além desta janela de oportunidades, para a ação política coletiva se consubstanciar, os desafiantes teriam de criar ou se apropriar de estruturas de mobilização preexistentes, como associações e redes de relacionamento, que dessem as bases organizacionais para a movimentação.

Os conceitos de estrutura de oportunidades políticas e de estruturas de mobilização davam conta das dimensões diretamente políticas da mobilização. Faltava, contudo, noção para tratar da faceta cultural nela envolvida. Aí morava o problema. Uma linha de vinculação entre cultura e conflito, quando Tilly adentrou o assunto nos anos 1970, vinha das reelaborações complicadas do já muito criticado conceito de ideologia. Doutro lado, estava o parsonianismo, que Tilly execrava, com sua sobrevalorização do papel integrador da cultura, substimando agency [agência] e conflito na explicação. A terceira via do interacionismo simbólico de Erving Goffman frisava justo a agency, as capacidades cognitiva e interpretativa dos atores sociais, nas interações conflituosas rotineiras, mas se centrava demais no agente para caber no esquema estruturalista tillyano.

Tilly, então, buscou amparo na historiografia francesa da escola dos Annales, que atentava para a longue durée dos processos culturais e a relacionava com transformações sociais de largo escopo. Mas enquanto os franceses falavam de "mentalidades" para designar as maneiras de pensar e viver de uma época inteira, Tilly queria assinalar as formas especificamente políticas de agir. Emprestou, então, da música a noção de "repertório" para designar o pequeno leque de maneiras de fazer política num dado período histórico. O conceito ressaltava a temporalidade lenta das estruturas culturais, mas dava espaço aos agentes, pois que a lógica volátil das conjunturas políticas os obrigaria a escolhas contínuas, conforme oportunidades e ameaças cambiantes - em contextos democráticos, passeatas são mais seguras que guerrilhas; em contextos repressivos, pode bem ser o contrário.

O conceito de "repertório de ação coletiva" visava, então, incluir cultura na teoria tillyana do processo político. Nasceu miúdo e cresceu, em reformulações sucessivas, no passo em que cresceu o próprio interesse tillyano na maneira pela qual a cultura molda possibilidades de ação no curso dos conflitos políticos.

\section{PASSO 1: REPERTÓRIO DE AÇÕES COLETIVAS (ANOS 1970)}

Tilly construiu sua teoria da mobilização política rechaçando explicações economicistas, deterministas e psicossociais da ação coletiva. Nesta conversa, apareceu a noção de "repertório de ações coletivas". Foi em 1976, em Getting together in Burgundy - 1675-1975. Tilly então compilava conflitos na imprensa oitocentista, em busca de padrões de ação coletiva. O conceito os descrevia, mas sem definição precisa, reportando "meios definidos de ação coletiva" e 
"um repertório familiar de ações coletivas que estão à disposição das pessoas comuns" (Tilly, 1976: 22), num dado momento histórico.

O autor abria aí agenda longeva e de dois eixos: a correlação entre mudança de repertório e mudança social, econômica e política, e o uso dos repertórios conforme as oportunidades políticas (Tilly, 1976: 22). Nasceu então sua primeira tipologia de dois repertórios sucessivos, um "do antigo regime", outro "popular" (Tilly, 1976: 29 e 35).

No clássico From mobilization to revolution, de 1978, dedicado a construir sua teoria da mobilização política, o termo reapareceu, generalizado:

Num dado ponto do tempo, o repertório de ações coletivas disponível para uma população é surpreendentemente limitado. Surpreendente, dadas as inúmeras maneiras pelas quais as pessoas podem, em princípio, empregar seus recursos ao perseguir fins comuns. Surpreendente, dadas as muitas maneiras pelas quais os grupos existentes perseguiram seus próprios fins comuns num tempo ou noutro (Tilly, 1978: 151-152).

Limitado porque demarca conjunto finito de maneiras historicamente inventadas de ação política, mas amplo, porque abarca várias culturas na mesma época:

A maioria dos norte-americanos do século XX, por exemplo, sabe como [...] organizar diferentes formas de manifestação: as marchas, as assembleias com discursos, a ocupação temporária de edifícios. [...]. Várias formas de manifestação pertencem ao repertório norte-americano do século XX - para não mencionar o canadense, japonês, grego, brasileiro e muitos outros. O repertório também inclui diversas variedades de greve, envio de petições, organização de grupos de pressão, e umas tantas outras maneiras de articular queixas e demandas (Tilly, 1978: 151-152).

O repertório é, então, um conjunto de formas de ação. Uma metáfora esclarece seu funcionamento: "Ele lembra uma linguagem rudimentar: tão familiar como o dia para seus usuários, e com toda a sua possível esquisitice [quaintness] ou incompreensibilidade para um estrangeiro" (Tilly, 1978: 156). Como a língua, vale para muitos e dura muito. Renova-se aos poucos. Tilly fala de mudança lenta, associada às grandes transformações sociais modernas - urbanização, industrialização, formação do Estado nacional. O repertório muda por "estandartização" ou "rotinização" (Tilly, 1978: 161 e 159), no sentido weberiano, conforme o uso, que adiciona novas formas de ação bem-sucedidas e subtrai as menos eficientes.

Mudanças que custam a sedimentar. Tilly distingue dois tipos históricos de repertório, um para o século XVIII, outro para o XIX. O conceito é então epocal, de escopo largo. Mas há sugestão de repertórios em convivência, peculiares a grupos de atores - a greve e os proletários -, ou a posições no espectro político - o "rígido", típico das autoridades, e o "flexível", a alternativa dos grupos fora das instituições políticas (Tilly 1978: 155-156). A distinção de polarizações políticas no uso de recursos culturais vinha afastar qualquer semelhança com 
um sistema de valores unificador, à moda parsoniana; apontava para o império dos conflitos mesmo no campo da cultura.

A greve é o grande exemplo tylliano. Cabe como uma luva para evidenciar um repertório de ação coletiva oitocentista. Repertório restrito a sintaxe, que os agentes preenchem com sua semântica. O flash vai para a pragmática, para o que as pessoas fazem durante um conflito. Tilly menciona símbolos, mas privilegia práticas - como as passeatas. O repertório surge como aglomerado de instrumentos para realização de interesses, sem significado em si mesmo.

Tilly não detalha o processo de apropriação do repertório pelos atores. Sabe-se que a relação é contingente, a escolha das formas depende de contexto, interlocutor, nível da ação. O ponto, neste momento, é evidenciar a existência de padrões de ação coletiva compartilhados - não seu uso.

Desta primeira formulação, sobra matéria aludida sem destrinchamento. Uma ambiguidade paira sobre a cobertura da noção: repertório é comum a época inteira, partilhado por todos, ou relativo a atores particulares? Outro nó é o de sua circulação e uso, ou como membros da vida social conhecem, manejam e transformam repertórios. Há menção ao "contágio" entre grupos e países como à invenção independente de mesmas maneiras em contextos díspares. Uma resposta difusionista, outra estruturalista. Como se conciliam ambas não se esclarece.

O enquadramento mais nas formas que nos conteúdos denuncia marca estrutural de nascença. Mas estruturalismo histórico, porque as formas de ação presentes se inventaram no curso de conflitos políticos passados.

\section{PASSO 2: REPERTÓRIO DE CONFRONTO (ANOS 1990)}

Repertório seguiu salpicando textos tillyanos sem teorização específica. Nos anos 1990, ilhado num mar de culturalistas, Tilly se viu compelido a voltar ao tema. A visada sobre as mobilizações coletivas da Teoria dos Novos Movimentos Sociais se implantara na New School, em Nova York, onde estavam Jean Cohen e Andrew Arato, epígonos da então novíssima teoria da sociedade civil. Cohen, em 1985, organizara dossiê da revista da instituição, a Social Research, sobre movimentos sociais. Seu artigo sintetiza o ataque culturalista a Tilly, coautores e seguidores: sua análise das mobilizações sobrevalorizaria dimensões estratégicas, deixando o simbolismo de lado. ${ }^{2}$

Tilly responderia em sequência de três artigos, nos quais o que era "repertório de ação coletiva" ressurge como "repertório de confronto". ${ }^{3}$ Esta adjetivação responde à crítica de que o conceito trataria de dinâmicas culturais, sem se fazer acompanhar de uma teoria da cultura. A especificação "de confronto" estreita o terreno, Tilly, assim, finca pé na sociologia política e dribla controvérsias da sociologia da cultura. Em "SM as historically specific clusters 
of political performance", de 1993-1994, a definição segue ressaltando formas de ação compartilhadas (Tilly, 1993-4: 41), sem mencionar formas de pensar volições, preferências, valores ou crenças.

Os artigos gêmeos, "Contentious repertoires in Great Britain, 1758-1834", versão 1993 e versão 1995, alteram este quadro, com um melhoramento teórico, outro empírico.

A ambiguidade anterior, entre repertório de ator e de época, se esclarece: um repertório não é peculiar a dado grupo, mas a certa estrutura de conflito. É sempre compartilhado:

[...] minha primeira formulação pressupunha que um ator singular (individual ou coletivo) possuía um repertório de meios e o empregava estrategicamente. Foi um erro. Cada rotina no interior de um repertório estabelecido de fato consiste de uma interação entre duas ou mais partes. Repertórios pertencem a conjuntos de atores em conflito, não a atores isolados (Tilly, 1995: 30).

O estruturalismo cede, com assimilação aggiornada do interacionismo simbólico. Termos aqui e ali - "arranjos sociais", "rotinas" - dão a pista, assim como a atenção para interações face a face e performances individuais ${ }^{4}$ (Tilly, 1995: 26-27). O conceito se torna relacional, iluminando a interação dos atores, nunca suas ações isoladas. ${ }^{5}$

Regressa a velha metáfora: o repertório é uma linguagem, estrutural e estruturante. ${ }^{6}$ Mas com tônica nova: a imagem agora apela tanto para a permanência quanto para o uso. O repertório é conhecimento social sedimentado, "entendimentos, memórias e acordos compartilhados", "relações sociais, significados e ações amalgamadas em padrões conhecidos e recorrentes" (Tilly, 1995: 30 e 27). Mas só vive quando ativado pelo uso, que faz a língua variar na fala, em dialetos, em sotaques. Para bem marcar, Tilly estofa esta metáfora com outras. Como no jazz, as "rotinas" de interação conflituosa, cheias de incidentes e contingências, obstam a repetição automática do repertório; antes, convidam os agentes a interpretar e improvisar. $\mathrm{O}$ andamento interacionista se estica na alegoria teatral: "Como suas contrapartes teatrais, repertórios de ação coletiva designam não performances individuais, mas meios de interação entre pares de grandes conjuntos de atores. Uma companhia, não um indivíduo, mantém um repertório" (Tilly, 1995: 27).

Semântica e agency aparecem: o repertório delimita o espectro de rotinas disponíveis, mas faculta aos agentes executá-las à sua maneira e escolher dentre elas estrategicamente, norteados pelo andamento da interação, com as opções dos contendores em ajuste recíproco e contínuo - bombas de gás lacrimogêneo da polícia revidadas com pedradas dos manifestantes, ou vice-versa:

[...] as pessoas num dado tempo e lugar aprendem a executar um número limitado de rotinas de ação coletiva alternativas, adaptando cada uma a circunstâncias imediatas e às reações de antagonistas, autoridades, aliados, observadores, objetos da ação, e outras pessoas de alguma maneira envolvidas na luta (Tilly, 1995: 27). 
A margem para interpretar e adaptar elucida como, apesar de dividirem um repertório, antagonistas se valem de rotinas diferentes ou das mesmas diferencialmente - um abaixo-assinado pró ou contra o aborto. O uso confere o sentido da ação.

Que conceito resulta desta nova embocadura?

\begin{abstract}
A palavra repertório identifica um conjunto limitado de rotinas que são aprendidas, compartilhadas e postas em ação por meio de um processo relativamente deliberado de escolha. Repertórios são criações culturais aprendidas, mas eles não descendem de filosofia abstrata ou tomam forma como resultado da propaganda política; eles emergem da luta. [...] Em qualquer ponto particular da história, contudo, elas [as pessoas] aprendem apenas um pequeno número de maneiras alternativas de agir coletivamente (Tilly, 1995: 26, grifo meu).
\end{abstract}

Definição com diferença sutil em relação à de 1993: “outlines” - contorno, esboço, resumo - dá lugar a "rotinas", termo caro ao interacionismo simbólico, remetendo ao hábito, ao costume, à tradição, à memória, à convenção, isto é, à cultura. Grande distância separa o repertório de formas de ação ["means"], de 1978, conceito vazado, da noção encarnada de "rotinas de interação", que abarca sentidos reciprocamente produzidos num conflito. Sua unidade passa a ser as rotinas convencionais - no sentido de tradicionais e de legítimas - de interação política típicas de uma época, ativamente adaptadas pelos agentes às suas circunstâncias e modificadas pelo uso. ${ }^{7}$

Os escritos tillyanos dos anos 1990 retomam o tema da mudança, inovação e difusão de repertórios, sublinhando o jogo estrutura e agency, longa e curta duração. O repertório de uma época é limitado - pequeno conjunto de rotinas de interação que sobreviveram ao teste da experiência - e limitador da capacidade inovadora dos atores, "eles geralmente inovam no perímetro do repertório existente em vez de romper inteiramente com as maneiras antigas" (Tilly, 1995: 27-28). As rotinas decantadas no repertório - como tradição ou memória política (Tilly, 1995: 27) -, contudo, só ganham vida se interações presentes se valerem delas. Como cada uso é peculiar - sempre reconhecemos uma passeata, sem que ela seja exatamente igual a nenhuma outra -, variações se inventam no curto prazo. No longo, sobrevivem e se difundem inovações bem-sucedidas, "emprestadas" por outros atores em novas circunstâncias.

Esta explicação histórico-estrutural da mudança dos repertórios é abalizada por banco de oito mil conflitos, garimpados em dez jornais britânicos, de 1758 a 1820 e de 1828 a 1835 . O caudaloso material forra a tese de um ponto de viragem entre dois macrorrepertórios de ação coletiva no Ocidente. Um paroquial, típico até o século XVIII, seria comunitário, visando assuntos locais; particular, com formas de protesto variáveis conforme lugar, ator e situação; e "bifurcado", pois que questões locais suscitariam ação direta, ao passo que as nacionais seriam mediadas por autoridades ou potentados locais. Nesta modalidade, Tilly (1995: 33) inclui manejo de símbolos, perturbação de cerimônias, invasões de 
terra, destruições de estoques e propriedades, com farto uso de violência. Seu exemplo são os "food riots", contra o preço de alimentos, mas também distúrbios em mercados, igrejas, festivais, em pequenas localidades, contra a cobrança de impostos e o alistamento militar, isto é, formas de resistência tópica ao processo de centralização política, que consolidava a autoridade de um Estado nacional.

Um novo repertório nasce no século XIX, depois de consolidados o Estado nacional centralizado e a sociedade urbano-industrial na Europa, pois "um estado crescentemente mais poderoso e exigente inspira uma nova forma de política. O repertório muda em conformidade" (Tilly, 1995: 35). Passou a nacional, com assuntos transversais às localidades e a reverberar a agenda do parlamento - direitos de minorias religiosas, reformas parlamentares, escravidão, impostos. E a "modular", pois mesmas formas - organização de associações e sindicatos, manifestações públicas, greves, passeatas, comícios, reuniões em pubs e cafés - serviriam a variados lugares, atores e assuntos e com menos violência (Tilly, 1995: 34).

Mudança estrutural e mudança cultural se conectam. Apoiado nos casos da Inglaterra e da França, Tilly distingue, assim, dois grandes grupos de formas de ação política ocidentais, um que antecede, outro que sucede as transformações que geraram a sociedade moderna. É 1830 aproximadamente o ponto de passagem, quando formas organizacionais e rotinas de interação confrontacional hoje triviais - partidos políticos, associações voluntárias, sindicatos, movimentos sociais, passeatas, greves e comícios (Tilly, 1995: 37) - teriam ascendido a maneiras generalizadas e socialmente legítimas de expressar reivindicações.

Estes artigos dos anos 1990, então, consolidam explicação histórico-estrutural para origem e mudança de repertórios e sofisticam o conceito, daí por diante propagado por seu autor e seguidores em trabalhos empíricos.

Conceito igualmente criticado. É que o empenho teórico em imantá-lo com cultura pela adição de rotinas pouco afetou a pesquisa empírica: os exemplos históricos arrolados seguem, qual em 1976, formas de ação - passeatas, greves, manifestações de rua. Cultura aparece como prática, sem dimensões cognitivas, afetivas, simbólicas ou morais. O sentido, por exemplo, ritual, das ações nunca entra em consideração.

\section{PASSO 3: REPERTÓRIO E PERFORMANCE (ANOS 2000)}

De fins dos anos 1990 até sua morte, em 2008, Tilly retomou o conceito de repertório em configuração nova: intelectual consolidado, estrela do departamento de sociologia da Universidade de Columbia, acumulando prêmios nos Estados Unidos e na Europa, traduzido em várias línguas e emulado por legião de seguidores. Desta posição de mérito reconhecido e autoridade avalizada, e apressado pelo câncer, Tilly escreveu livros de consolidação de seus assuntos 
prediletos e em autorrevisionismo, respondendo ao cenário político-intelectual do século XXI.

Com o 11 de setembro, a sociologia política se interessou pelas ações políticas violentas de nível global, ampliando seu escopo para além de conflitos sociais nacionais. Estudos sobre a globalização reavivaram o interesse pela difusão de ações e ideias entre esferas nacional e supranacional. Um dos livros de Tilly no novo milênio, com Sidney Tarrow e Doug McAdam, Dynamics of contention (2001), anda nestas duas direções, no anseio de abarcar todas as formas de mobilização e contramobilização, em escala planetária, numa única teoria do confronto político.

De outro lado, uma concepção mais ampla de cultura se impôs nas explicações das mobilizações políticas. O assunto quente do momento, o terrorismo islâmico global, mais os "cultural studies" resultantes do surto pós-estruturalista anterior, e o sucesso da grande síntese teórica de Bourdieu, que postula a cultura como campo de conflito, puseram os temas culturais no centro dos debates na sociologia política. Surgiram, então, novas noções ambicionando ajuntar cultura e ação política. Jasper (2007) chama a atenção para a eclosão de abordagens construcionistas, apropriando-se do conceito goffmaniano de "frames" para investigar como injustiças sociais são percebidas cognitivamente, construídas discursivamente e difundidas via mídia, movimentos sociais e Estado (por exemplo, Snow \& Benford, 2000). Cresceram também análises de retórica e semântica de discursos políticos e de narrativas de ativistas (Poletta, 2006); estudos sobre a presença de emoções coletivas nas mobilizações (Jasper \& Goodwin, 2004); rituais de ação política (Alexander, 2006); e identidades coletivas produzidas por meio da ação política (Melucci, 1995).

A abordagem estrutural da mobilização política, que Tilly inicialmente professara, sofreu sob esta vergasta culturalista. Nos últimos livros, admitiu excessos de estruturalismo e abriu ainda mais espaço à agency na análise das interações conflituosas. Isto sem beirar o construcionismo extremo (a realidade social como construção subjetiva dos agentes), andando antes na trilha de um "realismo relacional", que admite interpretações diferenciais, um perspectivismo, mas de situações sociais tangíveis, objetivas (Tilly, 2006: 47-48). Com esta nova abordagem, Tilly retomou o conceito de repertório, acoplando a ele a noção de performance e engolfando-o numa teoria da difusão.

Nos primeiros textos, o alvo de Tilly era detectar invariâncias de formas de ação em diferentes localidades e circunstâncias; nos últimos, é o uso do repertório em conflitos políticos, como os agentes o manejam em suas "performances". Este par (Tilly, 2008: xiv) tardio de repertório, outra ressonância de Goffman, vem desengessar seu estruturalismo político.

O capítulo final de Identities, boundaries \& social ties (2005) - "Invention, diffusion and transformation of the social movement repertoire" - marca este passo. Aí o repertório de confronto surge como "conjunto variável de perfor- 
mances" (Tilly, 2005: 216). Mas o raciocínio fica em suspenso, com a atenção posta na difusão de repertórios, caso da classe mais geral dos processos de "transferência política". A teoria se ilustra com a história de uma performance, a manifestação de rua. Evoluiu a partir de "tradições nacionais" distintas, aparecendo similar, no fim do século XIX, em países nórdicos, na França, na Inglaterra e em suas colônias inglesas (Tilly, 2005: 219). Quando transferida a novo lugar, regime, assunto ou ator, a manifestação de rua sofreria processos de negociação e adaptação e seria condicionada pela "cultura local" (Tilly, 2005: 222-223). Assim, as performances que compõem o repertório teriam duas faces. "Modulares", porque se pode reconhecer a mesma manifestação de rua em diferentes contextos. Mas cada qual é singularizada pelo uso, que agrega "símbolos e segredos locais" (Tilly, 2005: 223).

A transferência de repertórios envolve, então, escolhas e criatividade: "Muitas transferências políticas se centram em programas ou práticas específicas e envolvem deliberação consciente no ponto de chegada sobre se adotar um item e como [...]" (Tilly, 2005: 217). Escolha que encontra limites na tradição nacional e na cultura local, como nos constrangimentos da estrutura de oportunidades políticas e nos posicionamentos dos antagonistas. Embora sem definir, nem problematizar, Tilly, por primeira vez concede relevância explicativa à tradição.

Neste texto, Tilly também esboça seis mecanismos que, isolados ou combinados, estruturariam as transferências políticas: a "inovação tática", a modificação de uma rotina de interação conhecida, como a substituição de símbolos não verbais por outros escritos (caso dos slogans) ao longo do século XIX; a "barganha", a negociação da performance - os limites de uma passeata acertados entre manifestantes e polícia - no curso da interação; a "difusão negociada", a decisão de adotar inovação tática de outro grupo, lugar e assunto; a "mediação" [brokerage], quando um intermediário conecta dois atores, grupos, lugares antes isolados facilitando a circulação de repertórios; a "certificação/descertificação", uma autoridade social ou política endossa/condena a performance; e a "adaptação local”, modificação de uma inovação tática produzida alhures via adição de símbolos, rituais, pessoas ou conexões sociais locais (Tilly, 2005: 223-224).

Em Repertoires and regime, livro de 2006, consolida-se a teoria dos repertórios, que revisa e amplia reflexões dispersas em escritos anteriores, ${ }^{8}$ em três frentes. Uma é a especificação do conceito. A ideia de repertório como conjunto de performances se desenvolve. ${ }^{9}$ Performance suplanta rotina como unidade mínima do repertório, num esforço para adendar significados a repertório, assimilando temas afins com a sociologia da cultura, mas sem adentrar os meandros da discussão semântica. Assim, "identidade" é o que os atores definem como tal num conflito particular, por contraste e confronto com grupos rivais. Conceito relacional, não substantivo. Idem para "programa". Para Tilly, sentidos são inapartáveis das práticas, por isso, o melhor acesso a eles é a análise de performances - não de discursos. 


\begin{abstract}
Apresentar uma petição, fazer um refém, ou organizar uma manifestação constituem uma performance vinculando pelo menos dois atores, um reivindicador e um objeto das reivindicações. [...]. Performances se aglutinam em repertórios de rotinas reivindicatórias que empregam os mesmos pares de objeto de reivindicação: patrões e empregados, camponeses e proprietários de terra, facções nacionalistas rivais, e tantos outros (Tilly, 2006: 35).
\end{abstract}

As metáforas do jazz e do teatro retornam para descrever a relação repertório/performance, com a novidade do script - outra reverberação goffmaniana, sem que Goffman seja citado:

Se olharmos de perto uma reivindicação coletiva, veremos que casos particulares improvisam a partir de roteiros [scripts] compartilhados. [...]. A metáfora teatral chama a atenção para o caráter agrupado, aprendido, e ainda assim improvisado das interações [...]. Reivindicar usualmente se parece com jazz e commedia dell'arte mais do que com a leitura ritual de uma escritura sagrada. Como um trio de jazz ou grupo de teatro de improviso, as pessoas que participam em política confrontacional normalmente podem atuar em diversas peças, mas não numa infinidade delas $[\ldots]^{10}$ (Tilly, 2006: 35).

Distinguir teatro e ritual ${ }^{11}$ visa a acentuar criatividade e improviso, em vez de repetição, no uso do repertório, bem como enfatizar a margem de manobra dos atores, sua interpretação singular do script - fórmula de ação prevista no repertório. A criatividade envolvida nas performances é tal, que cada uma se particulariza. Esta tônica na agency se vislumbra, por exemplo, na afirmação de que o repertório inglês do século XIX só surgiu porque "novos usuários", defrontados com tarefas novas, julgaram os instrumentos disponíveis "inadequados para seus problemas e habilidades" (Tilly, 2006: 55).

O repertório aparece agora como feito e refeito, numa "história de contínua inovação e modulação" (2006: 55). Inovação abordada de dois ângulos. Na rotina social, o improviso dos atores modifica ligeiramente as performances previstas no repertório. Já nas crises e ciclos de protesto, há variações rápidas nas oportunidades políticas que, apreendidas diferencialmente pelos atores conforme a posição que ocupam, geram uma clivagem. Detentores de poder tendem a repetir estratégias bem-sucedidas no passado, fixando-se em repertórios rígidos; já os desafiantes adotam repertórios flexíveis (ou fortes), pois lhes interessa o fator surpresa que a inovação pode trazer. Na desmobilização, algumas inovações se decantam como componentes do repertório, outras desaparecem (Tilly, 2006: 44-45).

O que tria as duráveis das efêmeras? No plano micro, interesse e eficácia: perdura a inovação vantajosa para atores. Do ponto de vista macro, decantam as performances modulares - ponto desenvolvido por Tarrow (2009) -, que podem servir a muitos atores, assuntos, situações: a queima de sutiãs das feministas encontra raras ocasiões de uso fora de seu contexto de origem; já a resistência passiva de Gandhi pode ser usada por muitos movimentos. A modularidade facilita a transposição. ${ }^{12}$ 
A transferência de repertórios é, então, processo relacional e disputado (pelos agentes em interações conflituosas), histórica e culturalmente enraizado (o peso da tradição) e condicionado pelo ambiente político nacional (as estruturas de oportunidade). Experiências sociais específicas requisitam as transferências e condicionam a adoção, pois que os atores em litígio lidam com o repertório como os músicos de jazz com suas partituras: triam, mitigam, acentuam, exageram, conforme seus parceiros e seu público. Longe de espontâneo e solipsista, o improviso é calculado e orquestrado entre os membros da banda, para produzir certo efeito. O jogo entre a fórmula e a circunstância dá às performances duas caras, simultaneamente modular e singular.

O improviso dos atores ao criarem e recriarem interações sociais sobe a assunto central em Contentious performance ${ }^{13}$ (2008), última e, opinião de Tarrow (2008), melhor obra de Tilly e seu derradeiro "esforço para explicar, verificar e refinar os conceitos gêmeos de performance e repertório" (Tilly, 2008: xiv).

O argumento pouco muda em relação ao livro anterior: repertórios são aprendidos durante performances confrontacionais - só se aprende a marchar, marchando - e performances modificam os repertórios, contínua e incrementalmente. ${ }^{14}$ Continuidade e improviso (Tilly, 2008: 13-14). Mas a proeminência fica agora toda no uso: "No interior de um limitado conjunto [o repertório], os atores escolhem quais peças irão encenar aqui e agora, e em qual ordem" (Tilly, 2008: 14). Escolha, interpretação, compreensão, improviso, aprendizagem são termos que trazem para a abordagem dos processos políticos os contextos de microinteração social, a vida vivida. As contingências importam e muito.

De outra parte, Tilly acata as tantas críticas contra si por ignorar as narrativas dos agentes e se põe a trabalhar com elas (Tilly, 2008: 44). À sua maneira. De seu banco de dados gigante sobre "encontros confrontacionais" na Inglaterra oitocentista, destaca nas notícias de jornal os verbos que descrevem as ações e os categoriza - ataque; barganha; apoio. Com estes tipos empíricos demonstra de novo, na base da análise de discurso, o que demonstrara antes, analisando só ações: a passagem de um tipo a outro de repertório, do paroquial ao cosmopolitano (Tilly, 2008: 31-61). Tilly prova, assim, duas coisas, que sabe fazer análise de discurso tão bem quanto seus críticos e que a máxima valia que se pode tirar desta técnica é a mesma que se afere analisando interações. Como método, Tilly sempre confiou no levantamento de eventos, agora agregados em "episódios de confronto", mais que nas narrativas deles, porque concebia como unidade básica da vida social as interações conflitivas, não os discursos, daí sua defesa da "[...] necessidade de sólida evidência acerca da confrontação popular como um baluarte contra o ceticismo pós-moderno" (Tilly, 2008: 65).

Contudo, em seus últimos escritos, o interesse de Tilly pelas justificativas que os agentes constroem para suas ações inflou a ponto de dedicar- 
-lhes dois livros - Why? e Contentious conversations. Este passo e a simpatia pela "economia moral" de Thompson são indícios de que Tilly talvez adentrasse, se vivesse mais, as discussões sobre a moralidade.

Esta última abordagem tillyana dos repertórios privilegia, então, o improviso, a capacidade dos atores de selecionar e modificar as performances de um repertório, para ajeitá-las a programas, circunstância e tradição locais, isto é, ao contexto de sentido daquele grupo, naquela sociedade. O repertório só existe encarnado em performances confrontacionais. Tilly nunca arredou pé do postulado de que o eixo fundamental da vida social é o conflito, que ganha formas históricas peculiares. Qualquer invenção, uso, mudança de repertórios só podem ser entendidos neste esquadro histórico e relacional, que põe o confronto em primeiríssimo plano.

Embora este livro funcione como amarrilho de pontas soltas na análise de repertórios e performances, ${ }^{15}$ movimentos sociais e regimes políticos - e Tilly soubesse que era o seu último -, não sucumbiu à tentação da última palavra. Antes, multiplicou perguntas acerca do ritmo e modo da inovação, da transferência e adaptação de repertórios entre grupos, assuntos, regiões, países; do aprendizado, efetividade e impacto das performances sobre os atores que a mobilizam, autoridades, competidores, adversários, expectadores (Tilly, 2008: 28). Questões para as quais as respostas tillyanas deixavam insatisfeito o próprio Tilly, que encerrou o livro e a vida convidando outros a prosseguir com a tarefa: "[...] um livro que não levanta novas questões irresolvidas não merece ser escrito... ou lido!” (Tilly, 2008: 199).

\section{USOS}

Tilly partiu, em 1976, de uma noção de repertório como formas de ação reiteradas em diferentes tipos de conflito; abordagem estruturalista e racionalista, concentrada na ligação entre interesse e ação e privilegiando atores singulares. Trinta anos depois, o conceito se apresenta relacional e interacionista, privilegia a experiência das pessoas em interações conflituosas, e o uso e a interpretação dos scripts em performances, a nova unidade mínima do repertório. A adição de performance e o olho nas interações foi seu modo de adensar a agency e mitigar o estruturalismo de origem. Tilly começou botânico das formas de protesto, classificando, categorizando, discernindo padrões e permanências, e chegou a músico atento ao improviso e ao contingente na interpretação das partituras sociais, as interações.

A interpretação de Tilly pode se aplicar à carreira de seu conceito, apropriado em performances de outros intérpretes. Além da aplicação ipsis literis a novos casos, repertório ganhou especificações, contestações, dilatações, usos imprevistos. Dignas de nota, me parece, são duas variações. 
Uma toma o sentido primeiro de repertório, como conjunto de formas de ação, seja para expandi-lo, seja para contestá-lo. Elizabeth Clemens (2003) levou a fronteira empírica do conceito para além das estratégias de ação paraparlamentares, os exemplos tillyanos usuais, e encampou as geradas ou alteradas no interior de organizações sociais, cunhando a noção derivada de repertório institucional. Também Chabot (2000) extrapolou a noção, mudando de escala, para tratar da transferência transnacional de repertórios, mostrando como o movimento pelos direitos civis nos Estados Unidos se apropriou do repertório de resistência pacífica criado pelo movimento de independência da Índia. Jackie Smith (2001), estudando o protesto de Seattle, usou a pista tillyana da "adaptação tática", a transposição de formas de ação de repertórios de nível nacional para supranacional, para argumentar que a globalização afeta o uso e altera o repertório de ação coletiva. Do lado das contestações, Traugott (1995) questionou a divisão de Tilly em dois repertórios históricos distintos de formas de ação, demonstrando a permanência das barricadas francesas na longa duração. Já Stamatov (2010) acusou a exclusão das formas de ação religiosas, eixo do movimento anglo-americano antiescravidão, da fatura do conceito de repertório.

Outra apropriação do conceito andou mais na direção dos últimos livros de Tilly, abarcando semântica e interação. Steinberg (1995) considerou o conceito tylliano muito "instrumental" por privilegiar formas de ação, e propôs outro, complementar, "repertório discursivo", que seriam os meios pelos quais "contendores articulam coletivamente sua moralidade de demandas e remédios e sua visão ideológica ampla da igualdade e do direito de posse social. A luta é melhor conceitualizada como um diálogo ininterrupto entre detentores de poder e desafiantes" (Steinberg, 1995: 60). Esta perspectiva, ancorada na análise de discursos, à la Bakhtin, permitiria acessar o que em Tilly falta: a "moralidade coletiva" e a "gramática de motivos" da ação coletiva (Steinberg, 1995: 60-61, 74). Ann Swidler (1995; 2001) foi em direção assemelhada, preocupada em compatibilizar simbolismo e estratégias de ação. Swidler fala em repertórios culturais como compostos por conhecimento, habilidades e símbolos, que funcionariam como "caixa de instrumentos", nos quais os agentes selecionam os seus e lhes atribuem sentidos próprios, ao montar suas estratégias de ação. Também eu, analisando o movimento reformista brasileiro em fins do XIX, usei a especificação de Swidler para repertório, visando abarcar ações e textos (Alonso, 2002). Halfmann \& Young (2010), de sua parte, adicionaram moralidade ao açambarcar o conjunto de imagens e retórica disponível num dado tempo para evocar "fortes emoções negativas" na ideia de repertório moral, com a qual analisaram figuras grotescas produzidas no debate sobre aborto. Embora Halfmann e Young se furtem à definição precisa, tanto esta noção quanto a de Steinberg remetem à economia moral de Thompson, que Tilly namorava nos últimos trabalhos. Nos dois casos, o conceito quer abarcar padrões de sentido recorrentes numa época, mas usados em intenções diversas por grupos antagônicos. Já Auyero (2004) foi 
pelo lado da relação entre repertório e interação social, investigando o aprendizado de repertórios em rotinas sociais e episódios de conflito na Argentina contemporânea.

Então, o conceito foi espichado tanto em abrangência empírica quanto em reelaborações teóricas, ganhando novos usos.

Dentre os legatários da agenda tillyana, a liderança é de Sidney Tarrow, que há tempos modifica o conceito, pela adição, do lado da semântica, do conceito goffmaniano de enquadramentos interpretativos [frame], e pelo lado da sintaxe, com o desenvolvimento da ideia de modularidade. Tarrow (1993, 1998, 2010, 2008) também tem trabalhado com a inovação e difusão de repertórios, associando-as ao seu próprio conceito de ciclo de protestos.

A conciliação de repertório com frame, em que Tarrow insiste, deixava Tilly cético. Embora tenha subscrito a junção em livro dos dois com McAdam (2001), nunca se valeu desta solução em textos solo. É que enquanto os partidários da aplicação da framing analysis à interpretação da ação política exageram Goffman na direção cognitiva, Tilly tomou a herança interacionista pelo outro lado: o das trocas contingentes nas interações e conversações sociais - seu foco em Contentious conversations. Sua atenção para falas cresceu e muito, mas sempre as tomou como formas de interação social conflituosas. Este pé fincado no mundo das práticas nunca pisou o terreno movediço da pura análise de discurso.

A teoria tillyana dos repertórios legou agenda em duas direções. Uma é a casa das questões sobre transferência política e o peso que nela jogam a tradição e as oportunidades políticas locais ou como a experiência pregressa peculiar de um grupo ou país define e redefine repertórios alheios. Outra é a pesquisa sobre as performances, como a experiência presente, os sentidos e usos dos agentes em suas interações confrontacionais, transforma os repertórios.

Agenda que Tilly não quis fechar. O conceito de repertório, como todos os tillyanos, não é fórmula a ser aplicada a qualquer circunstância; é convite à pesquisa empírica de contextos históricos particulares, porque, embora, “[...] mecanismos recorrentes respondam pelas regularidades profundas do confronto através da história, apenas com eles nunca seremos capazes de dar conta de assuntos, atores, situações, e formas de interação que caracterizam uma dada região e era". Por isso, arremata com mais uma metáfora, a sociologia não pode viver sem história: "Como os geólogos lidando com massas de terra particulares e suas transformações, não temos escolha senão examinar a história relevante” (Tilly, 2006: 59). 


\section{NOTAS}

Todas as traduções foram feitas livremente pela autora. [N.E.]

1 Agradeço as sugestões de Brasílio Sallum Jr. e as recebidas em exposições no seminário "A Questão Nacional no Pensamento Político-social Brasileiro", USP/Cedec, 2010, e no Centro de Estudos e Pesquisas em História da Educação, UFMG, 2010, bem como por questões levantadas por alunos de minha disciplina Cultura e Ação Política, no Programa de Pós-Graduação em Sociologia da USP, em 2008 e 2011.

2 Trata-se do volume 52, $n^{\circ} 4$, Winter 1985, que se abre com o longo e polêmico artigo de Cohen, "Strategy or identity: new theoretical paradigms and contemporary social movements". O de Tilly - "Models and realities of popular collective action" - vinha em seguida, ensanduichado entre outros aderentes da linha dos Novos Movimentos Sociais: Alain Touraine, Claus Offe e Alberto Melucci e Klaus Eder.

3 Sigo aqui a solução adotada em Lua Nova (2009), no artigo de Tilly com Sidney Tarrow e Doug McAdam, que traduziu "contention" como "confronto" e "contentious" como "confrontacional", saída que evita a ambiguidade de "contencioso" em português, que remete ao vocabulário jurídico; em espanhol, contudo, têm-se traduzido o termo tanto como "contencioso" quanto como "beligerante".

4 Os programas dos cursos de Pós-Graduação de Tilly na Universidade de Columbia nesta época também o evidenciam: o de 1998 começava com Estigma.

5 Tilly em vários textos desta época se reporta ao "Manifesto for a relational sociology", de Mustafa Emirbayer (The American Journal of Sociology, 1997, 103/2), que, por sua vez, aponta certo consenso na teoria sociológica pós-anos 1970 na direção de tomar as relações sociais em vez de atores ou estruturas como unidade social básica.

Angela Alonso é professora do Departamento de Sociologia da Universidade de São Paulo (USP) e pesquisadora do Centro Brasileiro de Análise e Planejamento (Cebrap). 
6 “[...] um repertório de ações não se assemelha à consciência individual, mas a uma linguagem; embora indivíduos e grupos saibam e empreguem as ações em um repertório, as ações conectam conjuntos de indivíduos e grupos" (Tilly, 1995: 30).

7 Repertório de confronto é subtipo desta classe geral, restrito às interações conflituosas: "Quando as reivindicações em questão, se realizadas, viriam a afetar os interesses de outros atores, podemos falar em confronto. Assim, repertório de confronto são as maneiras estabelecidas pelas quais pares de atores fazem e recebem reivindicações concernentes aos interesses uns dos outros" (Tilly, 1995: 27).

8 O título engana porque o tema central é a mudança e variação de regimes políticos, mais que a investigação dos repertórios (Tilly, 2006: 35).

9 Repertório surge como "[...] conjunto limitado, familiar, historicamente criado de performances reivindicativas que, sob a maioria das circunstâncias, circunscreve em muito os meios pelos quais as pessoas se engajam em confrontos políticos" (Tilly, 2006: vii).

10 Este parágrafo reaparece ipsis literis em Contentious performances (Tilly, 2008: 14).

11 Maneira pela qual Tilly se afasta da análise neodurkheimiana da política à la Jeffrey Alexander (2006), com seu foco nos rituais.

12 Em Repertoires and regime, a teoria das transferências de repertórios volta, amparada em exemplos de várias partes do mundo do século XVIII ao XXI. E Tilly (2006: 41, 56-58) torna a associar repertórios e mudança social, com foco na afinidade entre tipos de repertório e tipos de regime político. Pedaços da história recente de Peru, Uganda, Estados Unidos, Marrocos, Jamaica, Índia ilustram como a diversidade de regimes políticos conforma ou requisita modalidades peculiares de repertórios de confronto. Reassoma a tese das oportunidades políticas: conforme a repressão/facilitação dos governos (Tilly, 2006: 74-75) as performances reivindicatórias ["claim-making performances"] se dividiram em prescritas, toleradas e proibidas, e os repertórios em tipos, conforme combinações entre grau de democracia (governos democráticos e não democráticos) e capacidade 
(alta ou baixa) do governo. Retorna, portanto, a tipologia de repertórios, com nome novo à modalidade contemporânea: cosmopolitano (Tilly, 2006: 54).

13 Apesar deste título, Tilly (2008: xv) se furta a discutir definições de performance que não a própria: "Com algum pesar, decidi não me engajar na vasta, caótica e escassamente conectada bibliografia sobre performance como um aspecto organizador da vida social”.

14 "Os participantes improvisam constantemente de duas maneiras diferentes: descobrindo como modelar as rotinas disponíveis para comunicar suas reivindicações, e respondendo às reações das outras pessoas [...]" (Tilly, 2008: 11-12).

15 Volta a tipologia dos repertórios - fraco e forte/rígido - e a ideia de repertórios comuns não a todos os atores de uma dada época, mas a pares de atores em interação conflituosa (Tilly, 2008; 15, 27, 78).

\section{REFERÊNCIAS BIBLIOGRÁFICAS}

Alexander, Jeffrey. From the depths of despair: performance, counterperformance and "September 11". In: Alexander, Jeffrey C.; Giesen, Bernhard \& Mast, Jason L. (orgs.). Social performance: symbolic action, cultural pragmatics and ritual. Cambridge: Cambridge University Press, 2006, p. 87-105.

Alonso, Angela. Ideias em movimento: a geração 1870 na crise do Brasil-Império. São Paulo: Paz e Terra, 2002.

Auyero, Javier. When everyday life, routine politics, and protest meet. Theory and Society, 2004, 33, p. 417-441.

Benford, Robert D. \& Snow, David A. Framing processes and social movements: an overview and assessment. Annual Review of Sociology, 2000, 26, p. 611-39.

Chabot, Sean. A culture of peace in motion: transnational diffusion of the Gandhian repertoire from India to the U. S. civil rights movement. International Journal of Humanities and Peace, 2000, 16/1. Disponível em <http://findarticles. com/p/articles/mi_hb155/is_1_16/ai_n28811583/>. Acesso em 15 maio 2012.

Clemens, Elisabeth. Organizational repertoires and institu- 
tional change: women's groups and the transformation of U. S. politics, 1890-1920. In: Goodwin, Jeff \& Jasper, James M. (orgs.). The social movements readers: cases and concepts. Oxford: Blackwell, 2003, p. 187-201.

Goodwin, Jeff \& Jasper, James M. (orgs.). Rethinking social movements: structure, meaning, and emotion. Nova York: Rowman \& Littlefield Publishers, 2004.

Halfmann, Drew \& Young, Michael P. War pictures: the grotesque as moral repertoire in the antislavery and antiabortion movements. Mobilization: An International Quarterly, 2010, 15/1, p. 1-24.

Jasper, James. Cultural approaches in the sociology of social movements. In: Klandermans, Bert \& Roggeband, Conny (orgs.). Handbook of social movement across disciplines. Nova York: Springer, 2010, p. 59-110

McAdam, Doug; Tarrow, Sidney \& Tilly, Charles. Dynamics of contention. Nova York: Cambridge University Press, 2001.

Melucci, Alberto. The process of collective identity. In: Johnston, Hank \& Klandermans, Bert (orgs.). Social movements and culture. Minneapolis: University of Minnesota Press, 1995, p. 41-63.

Polletta, Francesca. It was like a fever: storytelling in protest and politics. Chicago: Chicago University Press, 2006.

Smith, Jackie. Globalizing resistance: the Battle of Seattle and the future of social movements. Mobilization: An International Quarterly, 2001, 6, p. 1-19.

Stamatov, Peter. Activist religion, empire, and the emergence of modern long-distance advocacy networks. American Sociological Review, 2010, 75, p. 607-628.

Steinberg, Marc. The roar of the crowd: repertoires of discourse and collective action among the Spitafields Silk Weavers in nineteenth-century London. In: Traugott, Mark (org.). Repertoires and cycles of collective action. Durham, NC: Duke University Press, 1995, p. 57-88.

Swidler, Ann. Cultural power and social movements. In: Johnston, Hank \& Klandermans, Bert (orgs.). Social movements and culture. Minneapolis: University of Minnesota Press, 1995, p. 25-40. 
Talk of love: how culture matters. Chicago: University of Chicago Press, 2001.

Tarrow, Sidney. Modular collective action and the rise of the social movement: why the French revolution was not enough. Politics \& Society, 1993, 21/1, p. 69-90.

Charles Tilly and the practice of contentious politics. Social Movement Studies, 2008, 7, p. 225-246.

. Poder em movimento: movimentos sociais e confronto político. Petrópolis: Vozes, 2009.

. Dynamics of diffusion: mechanisms, institutions, and scale shift. In: Givan, Rebecca K.; Roberts, Kenneth M. \& Soule, Sarah A. (orgs.), The diffusion of social movements: actors, mechanisms, and political effects. Cambridge: Cambridge University Press, 2010, p. 204-220.

Cycles of collective action: between moments of madness and the repertoire of contention. In: Traugott, Mark (org.). Repertoires and cycles of collective action. Durham, NC: Duke University Press, 1995, p. 89-116.

Tilly, Charles. Social movement as historically specific clusters of political performances. Berkeley Journal of Sociology, 1993-4, 38, p. 1-30.

Identities, boundaries \& social ties. Boulder, CO/Londres: Paradigm Publishers, 2005.

Contentious performances. Cambridge: Cambridge University Press, 2008.

. Contentious repertoires in Great Britain, 1758-1834. In: Traugott, Mark (org.). Repertoires and cycles of collective action. Durham, NC: Duke University Press, 1995, p. 15-42.

. Contentious repertoires in Great Britain, 1758-1834. Social Science History, 1993, 17, p. 253-280.

. From mobilization to revolution. Boston: Wesley Publishing Co., 1978.

. Getting it together in Burgundy, 1675-1975. CRSO Working Paper U128, Center for Research on Social Organization, Universidade de Michigan, maio, 1976.

Regimes and repertoires. Chicago: University of Chicago Press, 2006. 
REPERTÓRIO, SEGUNDO CHARLES TILLY: HISTÓRIA DE UM CONCEITO

40

____. Why? What happens when people give reasons... and why. Princeton: Princeton University Press, 2006.

. As sociology meets history. Nova York: Academic Press, 1981.

; Tarrow, Sidney \& McAdam, Doug. Para mapear o confronto político. Lua Nova, 2009, 76, p. 11-48.

Traugott, Mark. Barricades as repertoire: continuities and discontinuities in the history of French contention. In: Traugott, Mark (org.). Repertoires and cycles of collective action. Durham, NC: Duke University Press, 1995, p. 16-43. 
Palavras-chave: Repertório; Charles Tilly; Cultura e ação política; Sociologia política; Movimentos sociais.

\section{Keywords:}

Repertoire; Charles Tilly; Culture and political action; Political sociology; Social movements.

\section{Resumo:}

O artigo problematiza a incorporação da dimensão cultural na explicação dos processos políticos a partir de uma reconstrução das várias formulações do conceito de repertório na sociologia de Charles Tilly, desde os anos 1970 até seus últimos trabalhos, em 2008. Mostra como Tilly partiu, em 1976, de uma noção de repertório como formas de ação reiteradas em diferentes tipos de conflito; abordagem estruturalista e racionalista, concentrada na ligação entre interesse e ação, e privilegiando atores singulares. Trinta anos depois, o conceito de repertório se apresenta relacional e interacionista, privilegia a experiência das pessoas em interações conflituosas, e o uso e a interpretação dos scripts em performances. Esta reformulação enfatiza a agency e afasta-se do estruturalismo anterior de Tilly. Argumenta-se que a interpretação de Tilly pode se aplicar à história de seu conceito, apropriado em performances de outros intérpretes. Além da sua aplicação a novos casos, repertório ganhou especificações, contestações, dilatações, e usos imprevistos.

\footnotetext{
Abstract:

Based upon a reconstruction of various formulations of the concept of repertoire in the sociological work of Charles Tilly from the 1970's until his last studies in 2008, this article problematizes the consideration of a cultural dimension in the explanation of political processes. It shows how Tilly departed from a notion of repertoire as forms of reiterated actions within different types of conflict, which indicates a structuralist and rationalist approach in joining interest and action and privileging individual actors. Thirty years later, "repertoire" becomes a relational and interactionist concept, privileging the experience of people in contentious interactions, and the use and interpretation of scripts in performances. This reconcepualization refocusses attention upon agency and deviates from Tilly's previous structuralism. This article argues that Tilly's reinterpretation of the concept can be applied to its history, its appropriation in performances of other interpreters. Besides its application to new cases, the concept of repertoire received new specifications, contestations, amplifications and was put to unpredicted uses.
} 